\title{
Physico-mechanical and structural properties of eggshell membrane gelatin- chitosan blend edible films
}

Mohammadi, Reza ; Mohammadifar, Mohammad Amin; Rouhi, Milad; Kariminejad, Mohaddeseh ; Mortazavian, Amir Mohammad ; Sadeghi, Ehsan; Hasanvand, Sara

Published in:

International Journal of Biological Macromolecules

Link to article, DOI:

10.1016/j.ijbiomac.2017.09.003

Publication date:

2018

Document Version

Peer reviewed version

Link back to DTU Orbit

Citation (APA):

Mohammadi, R., Mohammadifar, M. A., Rouhi, M., Kariminejad, M., Mortazavian, A. M., Sadeghi, E., \& Hasanvand, S. (2018). Physico-mechanical and structural properties of eggshell membrane gelatin- chitosan blend edible films. International Journal of Biological Macromolecules, 107(Part A), 406-412. https://doi.org/10.1016/j.ijbiomac.2017.09.003

\section{General rights}

Copyright and moral rights for the publications made accessible in the public portal are retained by the authors and/or other copyright owners and it is a condition of accessing publications that users recognise and abide by the legal requirements associated with these rights.

- Users may download and print one copy of any publication from the public portal for the purpose of private study or research.

- You may not further distribute the material or use it for any profit-making activity or commercial gain

- You may freely distribute the URL identifying the publication in the public portal 


\section{Accepted Manuscript}

Title: Physico-mechanical and structural properties of eggshell membrane gelatin- chitosan blend edible films

Authors: Reza Mohammadi, Mohammad Amin

Mohammadifar, Milad Rouhi, Mohaddeseh Kariminejad, Amir Mohammad Mortazavian, Ehsan Sadeghi, Sara

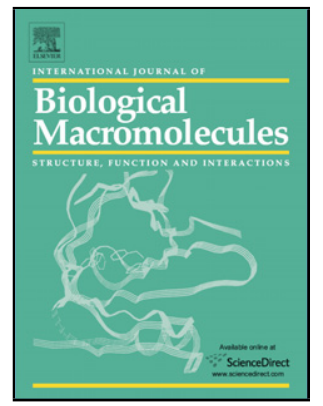

Hasanvand

PII:

DOI:

Reference:

S0141-8130(17)31010-3

http://dx.doi.org/10.1016/j.ijbiomac.2017.09.003

BIOMAC 8175

To appear in: $\quad$ International Journal of Biological Macromolecules

Received date: $\quad 19-3-2017$

Revised date: $\quad 30-8-2017$

Accepted date: $\quad 3-9-2017$

Please cite this article as: Reza Mohammadi, Mohammad Amin Mohammadifar, Milad Rouhi, Mohaddeseh Kariminejad, Amir Mohammad Mortazavian, Ehsan Sadeghi, Sara Hasanvand, Physico-mechanical and structural properties of eggshell membrane gelatin- chitosan blend edible films, International Journal of Biological Macromoleculeshttp://dx.doi.org/10.1016/j.ijbiomac.2017.09.003

This is a PDF file of an unedited manuscript that has been accepted for publication. As a service to our customers we are providing this early version of the manuscript. The manuscript will undergo copyediting, typesetting, and review of the resulting proof before it is published in its final form. Please note that during the production process errors may be discovered which could affect the content, and all legal disclaimers that apply to the journal pertain. 


\title{
Physico-mechanical and structural properties of eggshell membrane gelatin- chitosan blend edible films
}

Reza Mohammadi ${ }^{1}$, Mohammad Amin Mohammadifar ${ }^{2}$, Milad Rouhi ${ }^{1}$, Mohaddeseh Kariminejad ${ }^{1}$, Amir Mohammad Mortazavian*3, Ehsan Sadeghi ${ }^{1}$ and Sara Hasanvand ${ }^{1}$

${ }^{1}$ Department of Food Science and Technology, School of Nutrition Sciences and Food Technology, Kermanshah University of Medical Sciences, Kermanshah, Iran

${ }^{2}$ Research Group for Food Production Engineering, National Food Institute, Technical University of Denmark, SøltoftsPlads, 2800, Kgs. Lyngby, Denmark

${ }^{3}$ Department of Food Science and Technology, National Nutrition and Food Technology Research Institute, Faculty of Nutrition Sciences, Food Science and Technology, Shahid Beheshti University of Medical Sciences

* Correspondence to:

A.M.Mortazavian

Ph: + 98-21-223 76426

Fax: + 98-21-22360657

Email: mortazvn@sbmu.ac.ir/mortazvn@yahoo.com

\section{Highlights}

- $\quad$ - Physico-mechanical properties of composite edible films based on eggshell membrane gelatin extracted (G) and chitosan (Ch) were investigated

- - It was found that those films which prepared with the blend 75G: 25Ch and 50G: 50Ch had good mechanical and barrier properties.

- - FTIR was used to evaluate of structural properties and showed that between both polymers are total miscible

\begin{abstract}
This study investigated the physico-mechanical and structural properties of composite edible films based on eggshell membrane gelatin (G) and chitosan (Ch) (75G:25Ch, 50G:50Ch, 25G:75Ch). The results demonstrated that the addition of $\mathrm{Ch}$ increased elongation at break significantly $(p<0.05)$, but resulted in no significant change in tensile strength (TS) using 75G:25Ch, 50G:50Ch mixtures in comparison with gelatin-based film. The water solubility and water vapor permeability of the 50G:50Ch film decreased significantly compared to plain films (100G:0Ch and 0G:100Ch) and other composite films $(p<0.05)$.
\end{abstract}


Fourier transform infrared spectroscopy evaluation of structural properties showed that both polymers are totally miscible. Scanning electron microscopy was used to study the morphology of the composite films; it revealed a homogenous and compact structure in 75G:25Ch and 50G:50 Ch. Also, the chemical interactions introduced by the addition of chitosan to eggshell membrane gelatin as new resources could improve the films' functional properties.

Keywords: Eggshell membrane gelatin; ; , Chitosan, Edible film

\section{Introduction}

To protect industrial foods against oxygen, carbon dioxide, lipids, aroma, flavors and moisture, edible films and coating materials are used as substitutes for traditional non-biodegradable plastic films to provide both higher quality and extended shelf-life [1]. The most common sources of edible films are biopolymers such as proteins, carbohydrates, lipids or their blends $[2,3]$. One of the most important proteins is gelatin, which has a wide range of applications and functional properties, including film-forming ability, abundance and biodegradability. The major sources of gelatin for its application in industry are mammal products such as porcine and bovine bones and skin. However, the prevalence of prion diseases, foot-and-mouth diseases, avian influenza and religious objections has resulted in consumer anxiety about gelatin and gelatin-derived products [4]. Therefore, the use of other sources of gelatin such as fish skin is increasing [5]; however, eggshell membrane can also be an important source of gelatin and a replacement for mammalian sources. Genotoxicity, cytotoxicity and biochemical properties of eggshell membrane have demonstrated that eggshell membrane gelatin is benign in the risk of allergic and autoimmune reactions for different industrial applications $[6,7]$. Generally, gelatin is obtained by partially degrading collagen under specific conditions of temperature, $\mathrm{pH}$ and solvent [8-11]; the edible films obtained from gelatin can be used as a surface coating to protect food against oxygen and light due to its abundance, excellent biocompatibility and biodegradability and weak antigenicity $[9,12,13]$. Significant differences in molecular structure, amino 
acid sequence and functional properties of the extracted gelatin from different sources and with different extraction conditions have been shown.

Films produced from gelatin overall have appropriate optical properties, but have weak mechanical properties and water barriers, which are the principal disadvantages of gelatin-based films for applications such as coating and packaging food [14]. To overcome these limitations, gelatin eggshell membrane has been blended with other biopolymers, such as chitosan to improve the hydrocolloid film functionality

Chitosan, which is obtained from chitin naturally present in crustacean exoskeletons, is one of the most plentiful biopolymers. Chitosan-based materials have been used for a wide range of biomedical applications [3]. They have important advantages, such as biodegradability, non-toxicity, biocompatibility and functional properties as bacteriostatic and fungi stat $[9,15]$. Chemically, chitosan is a natural polymer, comprising $\beta$-(1,4)-linked N-acetyl-D-glucosamine and D-glucosamine units [9]. Chitosan-based composites are useful edible films because of their special characteristics including suitable mechanical properties, excellent film-forming capacity and lower gas transfer. Therefore, they can be used in the manufacture of edible films for covering foods and designing packaging structures $[8,16]$. The compact structure and enhanced physical, mechanical and transport properties are fundamental properties of edible films made from chitosan and gelatin blends, and are superior to those of films based on single components $[9,17,18]$. Furthermore, films made from blends of chitosan and gelatin have been demonstrated as homogeneous films because of the fine miscibility between both biopolymers [19]. This is elucidated by the formation of polyelectrolyte complexes (PECs) among electrostatic interactions and hydrogen bonding between the carboxylate groups of the gelatin and the amine groups of the chitosan [3,9]. Although many studies of chitosan and gelatin from different sources have been conducted, there is no previous report on the effect of different proportions of eggshell membrane gelatin and chitosan in the form of composites on the functional properties of eggshell membrane gelatin based. Thus, the specific objective of this study was 
to examine the physico-mechanical and structural properties of eggshell membrane gelatin- chitosan blend edible films.

\section{Materials and methods}

\subsection{Materials and reagents}

Commercial eggs were used to extract eggshell membrane. The external membranes were washed with distilled water and carefully and completely removed manually. Sodium hydroxide, sodium chloride, glycerol, acetic acid and tris (hydroxymethyl) aminomethane were purchased from Merck (Darmstadt, Germany). Pepsin enzyme with an activity of $750 \mathrm{U} / \mathrm{mg}$ proteins and chitosan (medium molecular weight, 75-85\% deacetylated) were bought from Sigma-Aldrich (St. Louis, MO, USA). In this study, all reagents and materials were analytical grade.

\subsection{Extraction of gelatin}

Gelatin was extracted from the eggshell membranes pursuant to the method of Mohammadi et al. (2016) with slight modifications [6]. The eggshell membranes were treated with 10 volumes (v/w) of alkali solution in $0.2 \mathrm{M} \mathrm{NaOH}$ for $18 \mathrm{~h}$ with continuous stirring to remove non-collagenous proteins. The supernatant was removed and the alkali-treated samples were washed with distilled water until neutral or faintly basic $\mathrm{pH}$ wash water was obtained. The pre-treated eggshell membranes were drenched in $0.5 \mathrm{~mol} / \mathrm{l}$ acetic acid with pepsin $(30 \mathrm{U} / \mathrm{mg})$ for $24 \mathrm{~h}$ with continuous stirring to swell the collagenous material in the eggshell membrane matrix. To remove undissolved debris, the mixture was filtered with two layers of cheesecloth. To inactivate proteases, the $\mathrm{pH}$ of the mixture was enhanced to 7.0 with tris (hydroxymethyl) aminomethane. The treated eggshell membrane mixtures were then incubated at $45^{\circ} \mathrm{C}$ for $6 \mathrm{~h}$ and stirred continuously to extract the gelatin from the eggshell membrane. To remove insoluble material, the mixtures were centrifuged at $15,000 \times \mathrm{g}$ for $20 \mathrm{~min}$ using a refrigerated centrifuge. The resultant filtrate was freezedried (ALPHA 2-4; Christ, Harz, Germany). Gelatins obtained were used to prepare the films.

\section{3. Determination of amino acid composition}


The gelatin samples were hydrolyzed in $6 \mathrm{~N} \mathrm{HCl}$ at $110^{\circ} \mathrm{C}$ for $24 \mathrm{~h}$. The hydrolysate was then vaporized, and the remainder was dissolved in $25 \mathrm{ml} 0.1 \mathrm{~N} \mathrm{HCl}$. A $0.4 \mathrm{ml}$ sample was applied to an amino acid analyzer (Shimadzu Seisakusho Co. Ltd., Kyoto, Japan).

\subsection{Preparation of the film-forming solutions and films}

Five formulations with diverse ratios of gelatin/chitosan (100G: 0Ch, 75G: 25Ch, 50G: 50Ch, 25G: 75Ch and 0G: 100Ch) were prepared. Single-gelatin film-forming solutions (G) were prepared at a concentration of $3 \%$ in distilled water for $30 \mathrm{~min}$, then stirred continuously while being heated at $45^{\circ} \mathrm{C}$. Chitosan solution (Ch) was prepared by dissolving chitosan at a concentration of $1.5 \%$ in $1 \%(\mathrm{v} / \mathrm{v})$ aqueous acetic acid. The film-forming solutions were prepared at different ratios of gelatin/chitosan (G75:Ch25, G50:Ch50, G25:Ch75). For $30 \mathrm{~min}$, all film-forming solutions were stirred and heated at $45{ }^{\circ} \mathrm{C}$ to obtain a good blend. Glycerol (25\% w/w polymer dry matter) was added to all film-forming solutions under stirring (30 min at $40{ }^{\circ} \mathrm{C}$ ). After homogenization, the gases in the solutions were removed under vacuum for 30 min to eliminate air bubbles, and $50 \mathrm{ml}$ of each solution were poured into plexiglass plates (14 $\mathrm{cm}$ diameter). Before testing, the dried films were conditioned at $25^{\circ} \mathrm{C}$ in a desiccator over a saturated solution of $\mathrm{NaBr}$ $(50 \pm 4 \% \mathrm{RH})$ for $72 \mathrm{~h}$.

\subsection{Film thickness}

To measure of the thickness of all composite films, a micrometer (Tokyo, Japan) was used and the measurements were taken to the nearest $0.001 \mathrm{~mm}$ at 10 random locations around each film. Average values were used for thickness determination.

\subsection{Mechanical properties}

To determine tensile strength (TS) and elongation at break (EAB), a universal traction-testing machine (SMT-20, Santam, Tehran, Iran) equipped with a $60 \mathrm{~N}$ load-cell was used, according to the ASTM standard method D 882-09 (2009) [20]. Equilibrated film specimens were mounted in the extension grips of the 
testing machine and stretched with a cross-head speed of $50 \mathrm{~mm} / \mathrm{min}$ until the samples broke. All determinations were the means of at least five measurements.

\subsection{Water solubility}

The films' water solubility was determined using the method reported by Cuq et al. (1992) [21]. To obtain the initial dry-mass content, four pieces of each film $(2 \mathrm{~cm} \times 2 \mathrm{~cm})$ were weighed $( \pm 0.0001 \mathrm{~g})$ and then dried in an air-circulating oven at $105{ }^{\circ} \mathrm{C}$ overnight [21]. After that, to determine their initial dry weight $\left(\mathrm{W}_{\mathrm{i}}\right)$, the films were re-weighed and recovered $( \pm 0.0001 \mathrm{~g})$. Film discs were mixed with $30 \mathrm{~mL}$ of distilled water at $25^{\circ} \mathrm{C}$ and stirred at room temperature for $24 \mathrm{~h}$. The remaining undissolved film was removed and dried at $105^{\circ} \mathrm{C}$ for $24 \mathrm{~h}$ and weighed $\left(\mathrm{W}_{\mathrm{f}}\right)$. Film solubility $(\mathrm{FS} \%)$ was calculated using the following equation:

$$
\mathrm{FS}(\%)=\frac{W_{i}-W_{f}}{W_{i}} \times 100
$$

where $\mathrm{W}_{\mathrm{i}}=$ initial dry film weight and $\mathrm{W}_{\mathrm{f}}=$ final dry film weight.

\subsection{Water vapor permeability}

To determine the films' water vapor permeability (WVP), the gravimetric method described in the ASTM E96-05 (2005) standard as adjusted to hydrophilic edible films by McHugh, Avena- Bustillos and Krochta (1993) was used [22]. Glass circular test cups with an internal diameter of $4 \mathrm{~cm}$ and a height of $10 \mathrm{~cm}$ were filled with distilled water $(15 \mathrm{~mL})$, and a film sample was placed in each cup. The cups were then covered and kept in a desiccator containing silica gel at room temperature and 0\% RH (0 Pa water-vapor pressure). The water was transferred along the films, adsorbed by the desiccant, and the film samples were weighed to determine the mass loss of the permeation cell. The mass loss of each sample was measured over $10 \mathrm{~h}$, with weights recorded at $2 \mathrm{~h}$ intervals. The slope of mass loss versus time was achieved with a linear regression of $\mathrm{R}^{2} \geq 0.99$. The WVP was measured as follows:

$$
\mathrm{WVP}=\frac{\mathrm{WVTR} \times \mathrm{L}}{\Delta \mathrm{P}}
$$


where WVTR is the transmission rate of water vapor $\left(\mathrm{g} \mathrm{mm} / \mathrm{kPa} \mathrm{h} \mathrm{m}^{2}\right)$ among the film, and measured from the slope of the linear line divided by the film exposed area (m2); L is the mean thickness of film (mm); and $\Delta \mathrm{P}$ is the difference of vapor pressure across the film $(\mathrm{KPa})$.

\subsection{Fourier transform infrared spectroscopy}

Before analysis, to obtain the greatest dehydration possible, all films were conditioned in a desiccators containing silica gel for 14 days. The structural interaction of blending in gelatin-based films was observed using a fourier transform infrared (FTIR) spectroscope (Bruker Banner Lane, Coventry, Germany). To obtain the films' FTIR spectra, each sample was placed into the spectroscope's crystal cell and mounted on the FTIR spectrometer. The spectrum was measured using an automatic signal over 16 scans in the range of $500-4000 \mathrm{~cm}^{-1}$ at a resolution of $4 \mathrm{~cm}^{-1}$, and the data were controlled against a background spectrum.

\subsection{Light transmission and transparency}

The rectangular film samples were placed directly onto the spectrophotometer cell. At selected wavelengths between 200 and $800 \mathrm{~nm}$, the barrier properties of gelatin films against ultraviolet (UV) and visible-light transmission were measured using a UV-visible recording spectrophotometer (Perkins Elmer Spectrophotometer, Korea) according to the method described by Fang, Tung, Britt, Yada and Dalgleish (2002) [23]. Film transparency was determined by the ratio between the absorbance at $600 \mathrm{~nm}$ (A600) and film thickness, calculated by the following equation:

Transparency value $=-\log \mathrm{T} 600 / \mathrm{x}$

where $\mathrm{T} 600$ is the fractional transmittance at $600 \mathrm{~nm}$ and $\mathrm{x}$ is the film thickness $(\mathrm{mm})$.

\subsection{Microstructure studies by scanning electron microscopy}

To visualize the microstructure of the composite edible films' cryo-fractured cross-section, a scanning electron microscope (SEM) (Cambridge Scan-360 microscope) at an accelerating voltage of $3.0 \mathrm{kV}$ was used. The film samples were immersed in liquid nitrogen and cryo-fractured. An SEM image was used to 
visualize the microstructure of the cryo-fractured cross-section of the edible films. Before visualization, film samples were coated with a thin gold layer to make them conductive. SEM images were taken at a $90^{\circ}$ angle to the surface to observe the films' cross section.

\subsection{Statistical analysis}

Statistical analyses of the data were analyzed using the SPSS statistical program (SPSS 23.0 for Windows, SPSS Inc., Chicago, IL, USA) using analysis of variance (ANOVA). The differences between means were evaluated by Duncan's Multiple Range $(p<0.05)$. All tests were repeated three times. 


\section{Results and discussion}

\subsection{Amino acid composition of gelatin}

Comparisons of amino acid composition between of gelatin extracted from the eggshell membrane, calf skin[24] fish skin[25] and pork skin[26] are shown in Table 1 . Similar results had been previously obtained from different sources [27]. The most abundant amino acid in the gelatin residues was glycine (318 residues per 1000); there were also relatively high contents of alanine (103 residues per 1000), proline (112 residues per 1000), glutamic acid/glutamine (98 residues per 1000), hydroxyproline (83 residues per 1000) and arginine (62 residues per 1000). Tryptophan was totally absent in eggshell membrane gelatin. Similar to other gelatins, the contents of tyrosine, histidine, cysteine, methionine and hydroxylysine were very low. The content of total imino acids (proline and hydroxyproline) in gelatin from the eggshell membrane were 195 residues per 1,000. Imino-acid content is one of the most important characteristics determining gelatins' potential use. These contents were lower than that reported for mammalian gelatins obtained from bovine hide (210 residues per 1000) and pork (223 residues per 1000) [28], and lower than that reported for tuna skin gelatin (185 residues per 1000), walleye pollock gelatin (184 residues per 1000) and cod skin gelatin (156 residues per 1000) [29]. This work agrees with earlier studies from other species in finding that amino acid content could vary with species and their habitat. This might be the reason for the differences in properties of gelatins between different species.

\subsection{Mechanical properties}

For packaging films, good mechanical properties such as TS and EAB are required for the films to resist external stress and maintain their integrity, as well as to act as barriers during the packaging process [30]. The TS, EAB and thickness of the gelatin-chitosan films and control films (gelatin or chitosan film) are shown in Table 2. Films from eggshell membrane gelatin (G100:0Ch) indicated average TS and EAB values of $32.521 \pm 0.995 \mathrm{MPa}$ and $3.52 \pm 0.74 \%$, respectively; these values were in the range reported by other 
researchers [31] and higher than that reported for fish gelatin-chitosan composite films by Hosseini et al. (2013) and lower than that reported for gelatin-chitosan blend edible films by Jridi et al. (2014) [13, 32]. In contrast, chitosan film demonstrated a significantly lower $(p<0.05)$ TS $(18.252 \mathrm{MPa})$ but a higher EAB $(39.821 \%)(p<0.05)$ than those of gelatin and composite films. Many researchers have reported that, generally, protein-based films have more desirable mechanical properties than films formed using only polysaccharides [9]. A comparison of composite edible films with gelatin films showed that the increased chitosan content in the former led to increased EAB values, which indicated stronger films; however, the presence of chitosan didn't significantly reduce the TS values. These results were completely different from those reported by other researchers [3, 32, 33], who had concluded that chitosan-based film was harder and tougher than gelatin-chitosan film, which they found to be soft and flexible. Overall, the mechanical properties of gelatin-chitosan films depend on multiple parameters including the molecular mass of the polymer of the chitosan, deacetylation degree, $\mathrm{pH}$ of the film-forming solution, drying conditions, solubilisation method, water content and film thickness. Hence, the comparison with the previous studies for TS tests suggests opposite conclusions [9, 18].

\subsection{Film solubility}

Solubility in water is one of the important properties of composite edible films. As shown in Table 2, the water solubility of eggshell membrane gelatin films was relatively high at around 91.33\%; this was in accordance with the values reported by Jridi et al. (2014) (90.68\%) for films obtained from cuttlefish-skin gelatin, and was considerably higher than the values reported for gelatin from cold-water fish skin $(63.81 \%$ ), bovine gelatin $(51.64 \%)$ catfish-skin gelatin and cod-skin gelatin $(25 \%)$ films $[9,13,32,34]$. This could be explained by higher prolin and hydroxyprolin content, the molecular weight of the extracted gelatin and the extraction method (enzyme or traditional). In contrast, chitosan film indicated a modest solubility in water $(52.35 \%)$. Some level of electrostatic forces and hydrogen bonding interaction between gelatin and chitosan were detected due to the addition of chitosan and indicated by the enhanced water resistance of 
eggshell membrane gelatin film. The films' decreased FS was related to blending with chitosan; this has also been reported by other researchers $[3,9,13,32]$. A $50 \%(w / w)$ proportion of gelatin content provided the most resistance to solubility and indicated considerable physical interference among the gelatin polypeptide chains within the film matrix [13].

\subsection{Water vapor permeability (WVP)}

Although commercially available synthetic polymers effectively control water vapor and gas permeability, edible films are used for packaging processed foods to prevent movement of gases and water; thus, their WVP should be as low as possible [21]. The WVP values for films prepared with eggshell membrane gelatin, chitosan and composite films are presented in Table 2. According to previous studies, the water vapor barrier of films is significantly $(p<0.05)$ affected by plasticizer concentration, film thickness and relative humidity gradient, gelatin origin and extraction method [35]. Increases in the level of water vapor transmission for gelatin films $\left(2.935 \pm 0.114 \times 10^{-11} \mathrm{~g} \mathrm{~m}^{-1} \mathrm{~s}^{-1} \mathrm{~Pa}^{-1}\right)$ were probably caused by an increase in the free volume of the film matrix, which increased the mobility of the polymeric chains, due to the incorporation of glycerol between protein chains and the presence of a broad range of hydrophilic amino acids (especially prolin and hydroxyl prolin) [35]. Furthermore, the extraction of gelatin from eggshell membrane using the enzymatic method, could be incorporated in the protein network, leading to reduced density of intermolecular interactions between gelatin polymeric networks [13]. The WVP of gelatin films has been previously investigated by other researchers. Comparisons between different authors are difficult due to differences in the gelatin extraction method, film manufacture and measurement procedures. Chitosan films demonstrated better WVP properties than gelatin films $\left(0.465 \times 10^{-11} \mathrm{~g} \mathrm{~m}^{-1} \mathrm{~s}^{-1} \mathrm{~Pa}^{-1}\right)$. As Ch was added, the WVP of composite films significantly decreased; for example, the declines for composite films with 75G:25Ch and 50G:50Ch ratios were more than 100 and $300 \%$ respectively $(\mathrm{p}<0.05)$. This could be because the chitosan might cross-link with gelatin by inter-molecular bonding (e.g. electrostatic and hydrogen bonding) and reduce the free volume or a densification of the network mesh of the polymeric matrix, thus reducing the diffusion rate of water molecules through the films and resulting in their lower 
WVP [32]. The improvement of the barrier permeability of chitosan by a gelatin addition in bovine hide gelatin and chitosan based films was reported by Pereda et al. (2011) [3]. In contrast, Kolodziejska and Piotrowska (2007) found that films based on cod-skin gelatin films had lower values for WVP [36].

\subsection{Light transmission and transparency}

Transmission of UV and visible light at selected wavelengths from 200-800 $\mathrm{nm}$ was determined. The values for the transparency of gelatin, chitosan and composite films at $600 \mathrm{~nm}$ are presented in Table 3 . Transmission in the visible range $(350-800 \mathrm{~nm})$ of gelatin films ranged between 58.21 and $90.73 \%$. The transmission of UV light was very low at $200 \mathrm{~nm}$ for all films (0.03 to $0.09 \%)$, and at $280 \mathrm{~nm}$ the composite films the transmission increased when chitosan was added ( $8.65 \%$ to $41.65 \%)$. Generally, by adding protein concentration, light transmission for both visible and UV ranges (200-800 nm) declined. This could mean that the gelatin-containing films effectively failed to block UV, causing discoloration, nutrient losses, offflavors and oxidative deterioration of packaged foods [16]. This result is similar to previous investigations of gelatin-based films, which showed that due to high amounts of aromatic amino acids such as tyrosine and phenylalanine, which absorb UV light, protein-based films have high UV barrier properties [16, 34, 37]. The reason for the difference in light transmission between films from different gelatin sources might be the differences in amino-acid composition, the degree of hydrolyzation and the aggregation or alignment of gelatin molecules due to gelatin enzymatic hydrolysis [38]. As shown in Table 3, the gelatin film was less [?] transparent than the composite and chitosan films (0.879 A600/mm). The resulting values were higher than those reported by Pereda et al. (2011) (0.68 A600/mm) and lower than those reported by Rivero et al. (2009) for bovine-gelatin films (0.97 A600/mm) [18]. Therefore, the addition of chitosan to gelatin lowered transparency values and, thus, increased opacity. This result is accordance with previous reports on gelatin-chitosan films [32]. The difference in transparency among films with different mass ratios of gelatin/chitosan could be caused by the difference in color, thickness, concentration of extracts and formation of poly-anion/cation complexes. Especially if the film is used as a coating or for improving product appearance, film opacity is one of the most critical film properties. 


\subsection{FTIR of films made from chitosan-gelatin blends}

Figure 1 shows the FTIR spectra of eggshell membrane gelatin, chitosan and composite films. Results obtained from chitosan film are in accordance with those described by other authors $[9,39,40]$. The spectra of eggshell membrane gelatin-based film showed main bands at approximately 3385.9 (NH-stretching coupled with hydrogen bonding (amides A)), 2946.2 (asymmetric stretching vibration of $\mathrm{C} \mathrm{H}$ and $\mathrm{NH}_{3}{ }^{+}$ (amide B)), 1654.1(C=O stretching/hydrogen bonding coupled with COO at $1636 \mathrm{~cm}^{-1}$ (amide-I)), 1552.5 (fluctuation mode is attributed to an out-of-phase combination of $\mathrm{CN}$ stretch and in-plane $\mathrm{NH}$ deformation modes of the peptide group at $1550 \mathrm{~cm}^{-1}$ (amide-II)) and $1239.2 \mathrm{~cm}^{-1}$ fluctuation in the plane of C-N and $\mathrm{N}-\mathrm{H}$ groups of bound amide or fluctuation of $\mathrm{CH}_{2}$ groups of glycine at $1239 \mathrm{~cm}^{-1}$ (amide- III). Liu et al. (2012) reported a different spectrum for gelatin-based film extracted from the skin of walleye pollock (Theragra chalcogramma), where amide A, amide I, amide II and amide III peaks were found at the wavelengths of 3299 (amide A), 1658 (amide I), 1544 (amide II) and $1243 \mathrm{~cm}^{-1}$ amide III, respectively [29]. Interaction of gelatins in edible films was affected by the functional group, secondary structure, gelatin source and methods of gelatin extraction (enzymatic or traditional). In composite film, because of the blend formulation, the intensity of the characteristic peaks was changed. From the spectra, the amide-I (CO) and amide-III (CN, NH) peaks of the composite film showed a slight but significant shift in the broad absorption band wavelengths from those of gelatin film with increases in the proportion of chitosan. In comparison to the secondary structure change, the amide II peak is considered to be much more sensitive to hydration; that might be due to feasible transformation in the protein secondary structure [9]. Furthermore, increasing the chitosan proportion in the film led to conformational changes in the gelatin polypeptide chains and subsequent decreases in the random coils, single helices and disordered structures, as demonstrated by the decreased intensity of the peak in the range of 1640 to $1552 \mathrm{~cm}^{-1}[9,32]$. Consequently, the molecular interactions among the biopolymers were observed in the spectra, and are not related to a simple mixture or networks in the blend structure. This effect was most obvious in the mixture with a ratio of $75 \mathrm{G}: 25 \mathrm{Ch}$, 
reaching intermediate amounts in mixtures 50G: 50Ch. Researchers proposed that this change may be a result of the presence of amino and carbonyl groups, since in general these groups interact electrostatically [32].

\subsection{Microstructural properties}

SEM was used to study microstructural changes in the edible films and to visualize the surface and crosssection topography of eggshell membrane gelatin, chitosan and composite edible films (Figure 2). Dense, homogenous and smooth structures without any large holes and pores were found using SEM testing of the fragment cross-section of composite edible films (75G:25Ch and 50G:50Ch). This represents excellent structural integrity compared to other blends made from proteins, such as quinoa protein/chitosan [39], whey-protein isolate gelatin composite [34] and oleic acid/CH films [41]. This result shows that the gelatin and chitosan were completely dissolvable and highly compatible at 75G: $25 \mathrm{Ch}$ and 50G: $50 \mathrm{Ch}$ due to associative interactions. The greater intermolecular aggregation in the three-dimensional network of eggshell membrane gelatin under cross-linking via covalent and non-covalent bonding was created by the addition of chitosan [29]. At the 25G:75Ch and 0G:100Ch levels, the free spaces were increased and the films' structure was loosened. Disconnection of film matrix could occur due to the high content of chitosan in the composite edible film and the low interaction of protein molecules. The higher TS (Table 2) of the films could be due to the condensed cross-section of the composite edible films with high contents of eggshell membrane gelatin, as shown by FTIR spectroscopy.

\section{Conclusions}

In the present report, gelatin extracted from eggshell membrane was used to produce edible films. The addition of chitosan with negatively charged polysaccharides showed that it could be a useful component to improve the mechanical properties and decrease the solubility and WVP of gelatin films. It was found that those films prepared with the blend 75G:25Ch and 50G:50Ch had good mechanical and barrier properties. These findings demonstrate these films' high potential for use in packaging materials to improve food quality, 
and further studies would be required to investigate potential performance improvement for industrialized use of the film in commercial food systems

\section{Acknowledgement}

We are thankful to the department of food science and technology, Kermanshah University of Medical Sciences, for support of this study. 


\section{References}

[1] N. Cao, X. Yang, Y. Fu, Effects of various plasticizers on mechanical and water vapor barrier properties of gelatin films, Food Hydrocolloids 23(3) (2009) 729-735.

[2] A. Al-Hassan, M. Norziah, Starch-gelatin edible films: water vapor permeability and mechanical properties as affected by plasticizers, Food Hydrocolloids 26(1) (2012) 108-117.

[3] M. Pereda, A. Ponce, N. Marcovich, R. Ruseckaite, J. Martucci, Chitosan-gelatin composites and bi-layer films with potential antimicrobial activity, Food Hydrocolloids 25(5) (2011) 1372-1381.

[4] D. Liu, L. Liang, J.M. Regenstein, P. Zhou, Extraction and characterisation of pepsin-solubilised collagen from fins, scales, skins, bones and swim bladders of bighead carp (Hypophthalmichthys nobilis), Food Chemistry 133(4) (2012) $1441-1448$.

[5] M. Gómez-Guillén, J. Turnay, M. Fernández-Diaz, N. Ulmo, M. Lizarbe, P. Montero, Structural and physical properties of gelatin extracted from different marine species: a comparative study, Food Hydrocolloids 16(1) (2002) 25-34.

[6] R. Mohammadi, M.A. Mohammadifar, A.M. Mortazavian, M. Rouhi, J.B. Ghasemi, Z. Delshadian, Extraction optimization of pepsin-soluble collagen from eggshell membrane by response surface methodology (RSM), Food chemistry 190 (2016) 186-193.

[7] K.J. Ruff, J.R. Endres, A.E. Clewell, J.R. Szabo, A.G. Schauss, Safety evaluation of a natural eggshell membranederived product, Food and chemical toxicology 50(3) (2012) 604-611.

[8] M. Aider, Chitosan application for active bio-based films production and potential in the food industry: Review, LWTFood Science and Technology 43(6) (2010) 837-842.

[9] N. Benbettaïeb, M. Kurek, S. Bornaz, F. Debeaufort, Barrier, structural and mechanical properties of bovine gelatinchitosan blend films related to biopolymer interactions, Journal of the Science of Food and Agriculture 94(12) (2014) 2409-2419.

[10] A. Haddar, S. Sellimi, R. Ghannouchi, O.M. Alvarez, M. Nasri, A. Bougatef, Functional, antioxidant and film-forming properties of tuna-skin gelatin with a brown algae extract, International journal of biological macromolecules 51(4) (2012) 477-483. 
[11] W. Liu, G. Li, Y. Miao, X. Wu, PREPARATION AND CHARACTERIZATION OF PEPSIN-SOLUBILIZED TYPE I COLLAGEN FROM THE SCALES OF SNAKEHEAD (OPHIOCEPHALUS ARGUS), Journal of food biochemistry 33(1) (2009) 20-37.

[12] M. Gómez-Guillén, M. Pérez-Mateos, J. Gómez-Estaca, E. López-Caballero, B. Giménez, P. Montero, Fish gelatin: a renewable material for developing active biodegradable films, Trends in Food Science \& Technology 20(1) (2009) 3-16. [13] M. Jridi, S. Hajji, H.B. Ayed, I. Lassoued, A. Mbarek, M. Kammoun, N. Souissi, M. Nasri, Physical, structural, antioxidant and antimicrobial properties of gelatin-chitosan composite edible films, International journal of biological macromolecules 67 (2014) 373-379.

[14] V. Chiono, E. Pulieri, G. Vozzi, G. Ciardelli, A. Ahluwalia, P. Giusti, Genipin-crosslinked chitosan/gelatin blends for biomedical applications, Journal of Materials Science: Materials in Medicine 19(2) (2008) 889-898.

[15] P. Dutta, S. Tripathi, G. Mehrotra, J. Dutta, Perspectives for chitosan based antimicrobial films in food applications, Food chemistry 114(4) (2009) 1173-1182.

[16] J.T. Martins, M.A. Cerqueira, A.A. Vicente, Influence of $\alpha$-tocopherol on physicochemical properties of chitosanbased films, Food Hydrocolloids 27(1) (2012) 220-227.

[17] J. Gómez-Estaca, A.L. de Lacey, M. López-Caballero, M. Gómez-Guillén, P. Montero, Biodegradable gelatinchitosan films incorporated with essential oils as antimicrobial agents for fish preservation, Food microbiology 27(7) (2010) 889-896.

[18] S. Rivero, M. García, A. Pinotti, Composite and bi-layer films based on gelatin and chitosan, Journal of Food Engineering 90(4) (2009) 531-539.

[19] M.Z. Elsabee, E.S. Abdou, Chitosan based edible films and coatings: a review, Materials Science and Engineering: C 33(4) (2013) 1819-1841.

[20] A. Intl, Standard test method for tensile properties of thin plastic sheeting. D 882-01, Annual book of ASTM standards. Philadelphia, Pa.: ASTM Intl.p (2001) 162-70.

[21] N. Gontard, S. Guilbert, J.L. CUQ, Edible wheat gluten films: influence of the main process variables on film properties using response surface methodology, Journal of food science 57(1) (1992) 190-195.

[22] T.H. McHugh, R. Avena-Bustillos, J. Krochta, Hydrophilic edible films: modified procedure for water vapor permeability and explanation of thickness effects, Journal of Food Science 58(4) (1993) 899-903. 
[23] Y. Fang, M. Tung, I. Britt, S. Yada, D. Dalgleish, Tensile and barrier properties of edible films made from whey proteins, Journal of Food Science 67(1) (2002) 188-193.

[24] J.-W. Woo, S.-J. Yu, S.-M. Cho, Y.-B. Lee, S.-B. Kim, Extraction optimization and properties of collagen from yellowfin tuna (Thunnus albacares) dorsal skin, Food Hydrocolloids 22(5) (2008) 879-887.

[25] Y.-R. Huang, C.-Y. Shiau, H.-H. Chen, B.-C. Huang, Isolation and characterization of acid and pepsin-solubilized collagens from the skin of balloon fish (Diodon holocanthus), Food Hydrocolloids 25(6) (2011) 1507-1513.

[26] P. Zhou, S.J. Mulvaney, J.M. Regenstein, Properties of Alaska pollock skin gelatin: a comparison with tilapia and pork skin gelatins, Journal of Food Science 71(6) (2006).

[27] P. Kittiphattanabawon, S. Benjakul, W. Visessanguan, H. Kishimura, F. Shahidi, Isolation and characterisation of collagen from the skin of brownbanded bamboo shark (Chiloscyllium punctatum), Food Chemistry 119(4) (2010) 15191526.

[28] J. Gómez-Estaca, P. Montero, F. Fernández-Martín, M. Gómez-Guillén, Physico-chemical and film-forming properties of bovine-hide and tuna-skin gelatin: a comparative study, Journal of Food Engineering 90(4) (2009) 480-486. [29] Z. Liu, X. Ge, Y. Lu, S. Dong, Y. Zhao, M. Zeng, Effects of chitosan molecular weight and degree of deacetylation on the properties of gelatine-based films, Food Hydrocolloids 26(1) (2012) 311-317.

[30] M. Rao, S. Kanatt, S. Chawla, A. Sharma, Chitosan and guar gum composite films: Preparation, physical, mechanical and antimicrobial properties, Carbohydrate Polymers 82(4) (2010) 1243-1247.

[31] S. Rawdkuen, S. Sai-Ut, S. Benjakul, Properties of gelatin films from giant catfish skin and bovine bone: a comparative study, European Food Research and Technology 231(6) (2010) 907-916.

[32] S.F. Hosseini, M. Rezaei, M. Zandi, F.F. Ghavi, Preparation and functional properties of fish gelatin-chitosan blend edible films, Food chemistry 136(3) (2013) 1490-1495.

[33] J. Gómez-Estaca, M. Gómez-Guillén, F. Fernández-Martín, P. Montero, Effects of gelatin origin, bovine-hide and tuna-skin, on the properties of compound gelatin-chitosan films, Food Hydrocolloids 25(6) (2011) 1461-1469.

[34] M. Jiang, S. Liu, X. Du, Y. Wang, Physical properties and internal microstructures of films made from catfish skin gelatin and triacetin mixtures, Food hydrocolloids 24(1) (2010) 105-110. 
[35] M. Jridi, N. Souissi, A. Mbarek, G. Chadeyron, M. Kammoun, M. Nasri, Comparative study of physico-mechanical and antioxidant properties of edible gelatin films from the skin of cuttlefish, International journal of biological macromolecules 61 (2013) 17-25.

[36] I. Kołodziejska, B. Piotrowska, The water vapour permeability, mechanical properties and solubility of fish gelatinchitosan films modified with transglutaminase or 1-ethyl-3-(3-dimethylaminopropyl) carbodiimide (EDC) and plasticized with glycerol, Food Chemistry 103(2) (2007) 295-300.

[37] A. Leerahawong, R. Arii, M. Tanaka, K. Osako, Edible film from squid (Todarodes pacificus) mantle muscle, Food Chemistry 124(1) (2011) 177-182.

[38] M. Nagarajan, S. Benjakul, T. Prodpran, P. Songtipya, Properties of bio-nanocomposite films from tilapia skin gelatin as affected by different nanoclays and homogenising conditions, Food and Bioprocess Technology 7(11) (2014) 32693281.

[39] L.E. Abugoch, C. Tapia, M.C. Villamán, M. Yazdani-Pedram, M. Díaz-Dosque, Characterization of quinoa proteinchitosan blend edible films, Food Hydrocolloids 25(5) (2011) 879-886.

[40] M. Kurek, C.-H. Brachais, C.M. Nguimjeu, A. Bonnotte, A. Voilley, K. Galić, J.-P. Couvercelle, F. Debeaufort, Structure and thermal properties of a chitosan coated polyethylene bilayer film, Polymer degradation and stability 97(8) (2012) 1232-1240.

[41] M. Vargas, A. Albors, A. Chiralt, C. González-Martínez, Characterization of chitosan-oleic acid composite films, Food Hydrocolloids 23(2) (2009) 536-547. 


\section{FIGURE CAPTIONS}

Figure. 1. FTIR spectra of eggshell membrane gelatin, chitosan and composite films

Figure. 2. SEM micrographs (cryo-fractured cross-section) of eggshell membrane gelatin, chitosan and composite films.

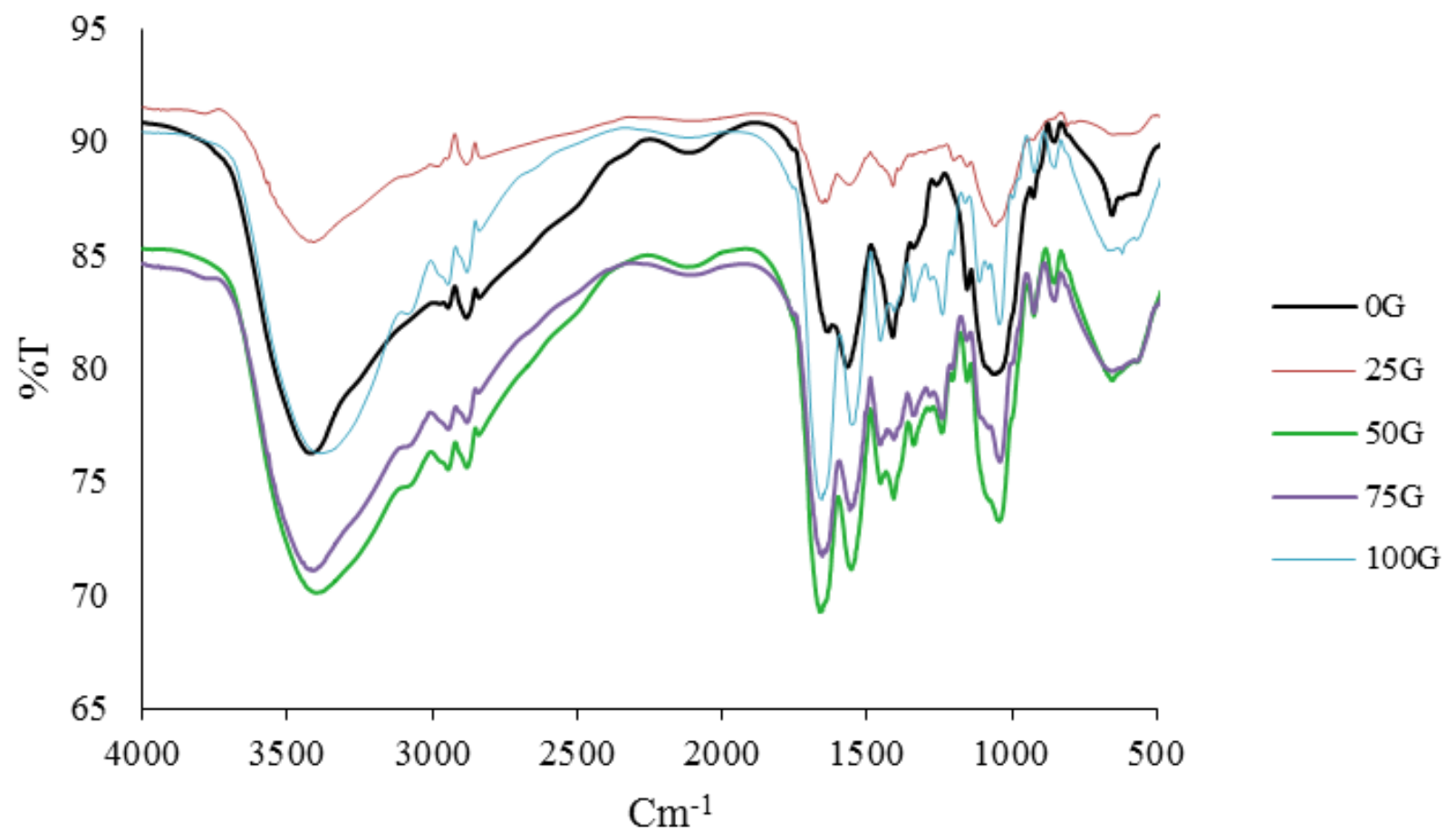

Figure 1 

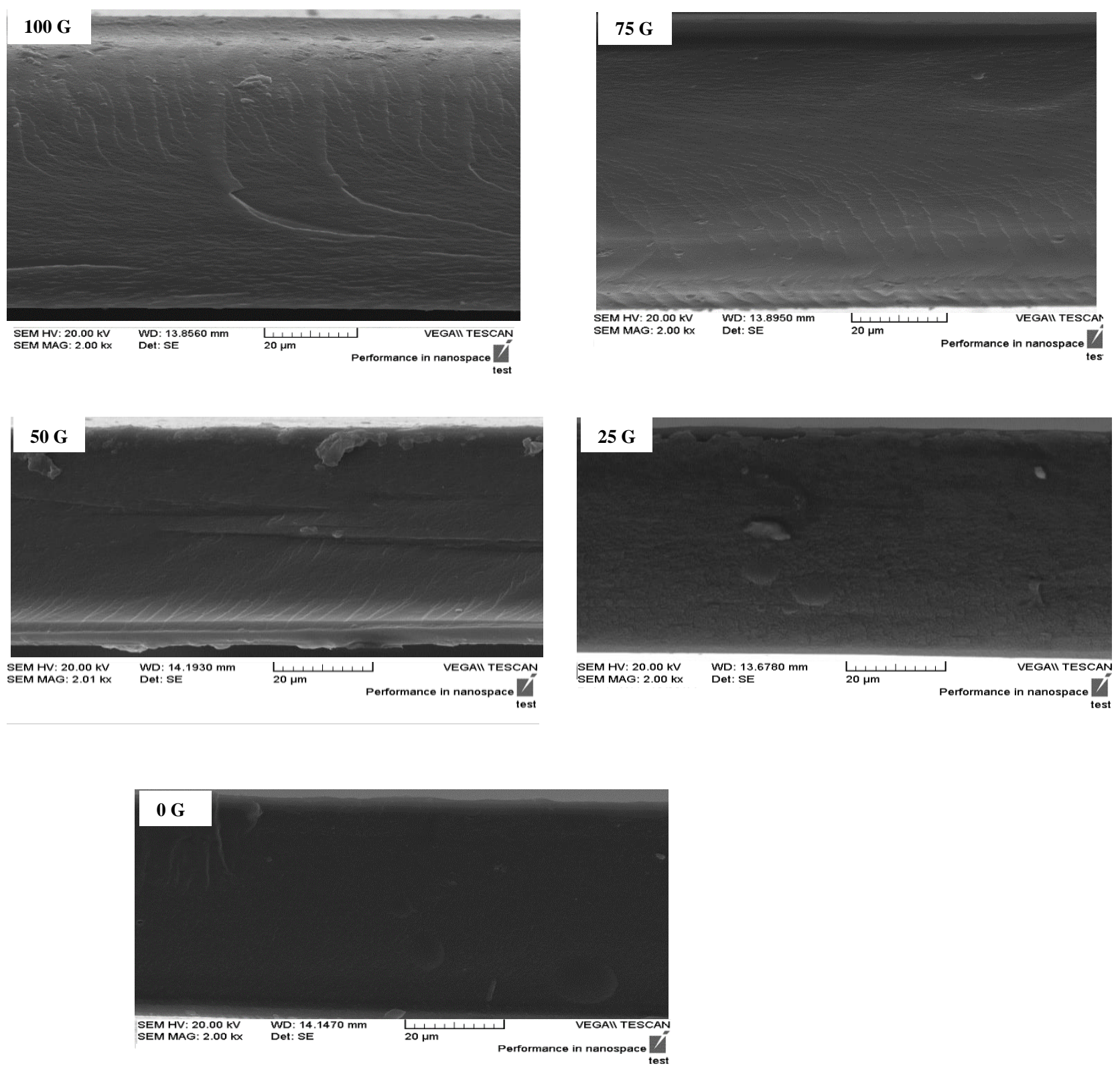

Figure. 2. 
Table 1. Amino acids compositions of eggshell membrane compared to Calf skin [39], fish skin[40] and pork skin[41].

\begin{tabular}{lcccc}
\hline Amino acid & Eggshell & Calf skin & Fish & Pork \\
\hline Aspartic acid & 55 & 68 & 50 & 46 \\
Glutamic acid & 98 & 109 & 69 & 72 \\
Threonine & 23 & 20 & 27 & 18 \\
Serine & 34 & 35 & 37 & 35 \\
Glycine & 318 & 241 & 340 & 330 \\
Alanine & 103 & 78 & 133 & 112 \\
Valine & 20 & 28 & 23 & 26 \\
Methionine & 9 & ND & 11 & 4 \\
Cysteine & 4 & 10 & 2 & ND \\
Isoleucine & 13 & 17 & 12 & 10 \\
Leucine & 24 & 33 & 20 & 24 \\
Tyrosine & 6 & 6 & 4 & 3 \\
Phenylalanine & 8 & 24 & 14 & 4 \\
Histidine & 7 & 11 & 6 & 49 \\
Arginine & 62 & 73 & 50 & 27 \\
Lysine & 21 & 40 & 28 & 91 \\
Hydroxyproline & 83 & 99 & 68 & 132 \\
Proline & 112 & 117 & 106 & 223 \\
Imino acids & 195 & 208 & 174 & \\
\hline
\end{tabular}

Table 2. Mechanical properties, thickness, WVP and water solubility of composite films.

\begin{tabular}{|c|c|c|c|c|c|}
\hline Films & TS (MPa) & EAB (\%) & $\begin{array}{l}\text { WVP } \\
\left(\times 10^{-11} \mathrm{~g} \mathrm{~m}^{-1}\right. \\
\left.\mathrm{s}^{-1} \mathrm{~Pa}^{-1}\right)\end{array}$ & $\begin{array}{l}\text { Film } \\
\text { solubility }\end{array}$ & $\begin{array}{l}\text { Thickness } \\
(\mathrm{mm})\end{array}$ \\
\hline $100 \mathrm{G}: 0 \mathrm{Ch}$ & $\begin{array}{l}32.521 \pm \\
0.99^{\mathrm{a}}\end{array}$ & $\begin{array}{l}3.52 \pm \\
0.74 \text { e }\end{array}$ & $\begin{array}{l}2.935 \pm \\
0.114^{\mathrm{a}}\end{array}$ & $\begin{array}{l}91.33 \pm 1.06 \\
\text { a }\end{array}$ & $\begin{array}{l}0.083 \pm \\
0.006^{\mathrm{a}}\end{array}$ \\
\hline $75 \mathrm{G}: 25 \mathrm{Ch}$ & $\begin{array}{l}31.624 \pm \\
1.15^{\mathrm{a}}\end{array}$ & $\begin{array}{l}16.04 \pm \\
0.32^{d}\end{array}$ & $\begin{array}{l}1.023 \pm \\
0.071^{\mathrm{b}}\end{array}$ & $\begin{array}{l}56.28 \pm 0.66 \\
\mathrm{~b}\end{array}$ & $\begin{array}{l}0.067 \pm \\
0.008^{b}\end{array}$ \\
\hline 50G:50Ch & $\begin{array}{l}28.167 \pm \\
0.81^{b}\end{array}$ & $\begin{array}{l}21.731 \pm \\
0.17^{\mathrm{c}}\end{array}$ & $\begin{array}{l}0.827^{ \pm} \\
0.093^{c}\end{array}$ & $\begin{array}{l}48.33 \pm 1 / 21 \\
\text { c }\end{array}$ & $\begin{array}{l}0.065 \pm \\
0.002^{b}\end{array}$ \\
\hline $25 \mathrm{G}: 75 \mathrm{Ch}$ & $\begin{array}{l}20.773 \pm \\
1.33^{\mathrm{c}}\end{array}$ & $\begin{array}{l}25.921 \pm \\
0.36^{\mathrm{b}}\end{array}$ & $\begin{array}{l}0.573 \pm \\
0.102^{\mathrm{d}}\end{array}$ & $\begin{array}{l}50.45 \pm 0.45 \\
\text { d }\end{array}$ & $\begin{array}{l}0.057 \pm \\
0.005^{c}\end{array}$ \\
\hline 100Ch:0G & $\begin{array}{l}18.252 \pm \\
0.94^{\mathrm{b}}\end{array}$ & $\begin{array}{l}39.821 \pm \\
0.29^{\text {a }}\end{array}$ & $\begin{array}{l}0.465 \pm \\
0.057^{\mathrm{e}}\end{array}$ & $\begin{array}{l}52.35 \pm 1.47 \\
\mathrm{e}\end{array}$ & $\begin{array}{l}0.047 \pm \\
0.007^{\mathrm{d}}\end{array}$ \\
\hline
\end{tabular}


Table 3. Light transmission and transparency.

\begin{tabular}{lllllllll}
\hline Films & \multicolumn{9}{c}{$\begin{array}{l}\text { Wavelength(nm) } \\
\end{array}$} & & & & & \multicolumn{2}{c}{$\begin{array}{c}\text { Transparency } \\
\text { values }\end{array}$} \\
& 200 & 280 & 350 & 400 & 500 & 600 & 800 & \\
\cline { 2 - 7 } 100G:0Ch & 0.03 & 8.65 & 58.21 & 65.31 & 73.26 & 84.53 & 90.73 & 0.879 \\
75G:25Ch & 0.03 & 10.32 & 59.83 & 68.29 & 74.35 & 85.11 & 91.17 & 1.045 \\
50G:50Ch & 0.04 & 21.30 & 54.31 & 68.73 & 71.14 & 84.79 & 90.65 & 1.102 \\
25G:75Ch & 0.06 & 32.44 & 56.47 & 67.45 & 70.64 & 83.42 & 90.55 & 1.381 \\
Ch100:0G & 0.09 & 41.65 & 57.19 & 63.74 & 68.40 & 81.37 & 90.10 & 1.905 \\
\hline
\end{tabular}

